\title{
Intuitive Eating Behavior and Obesity among Adolescents in Malaysia
}

Rosmaliza Muhammad, Norazmir Md Nor, Emmy Hainida Khairul Ikram, Nurul Fadly Habidin, Norhayati Mohd Yusof, Norhidayah Abdullah, Mohd Shazali Md Sharif

To Link this Article: http://dx.doi.org/10.6007/IJARBSS/v11-i8/10733 DOI:10.6007/IJARBSS/v11-i8/10733

Received: 11 June 2021, Revised: 16 July 2021, Accepted: 29 July 2021

Published Online: 04 August 2021

In-Text Citation: (Muhammad et al., 2021)

To Cite this Article: Muhammad, R., Nor, N. M., Ikram, E. H. K., Habidin, N. F., Yusof, N. M., Abdullah, N., \& Sharif, M. S. M. (2021). Intuitive Eating Behavior and Obesity among Adolescents in Malaysia. International Journal of Academic Research in Business and Social Sciences, 11(8), 311-316.

Copyright: @ 2021 The Author(s)

Published by Human Resource Management Academic Research Society (www.hrmars.com) This article is published under the Creative Commons Attribution (CC BY 4.0) license. Anyone may reproduce, distribute, translate and create derivative works of this article (for both commercial and non-commercial purposes), subject to full attribution to the original publication and authors. The full terms of this license may be seen at: http://creativecommons.org/licences/by/4.0/legalcode

Vol. 11, No. 8, 2021, Pg. 311 - 316

Full Terms \& Conditions of access and use can be found at http://hrmars.com/index.php/pages/detail/publication-ethics 


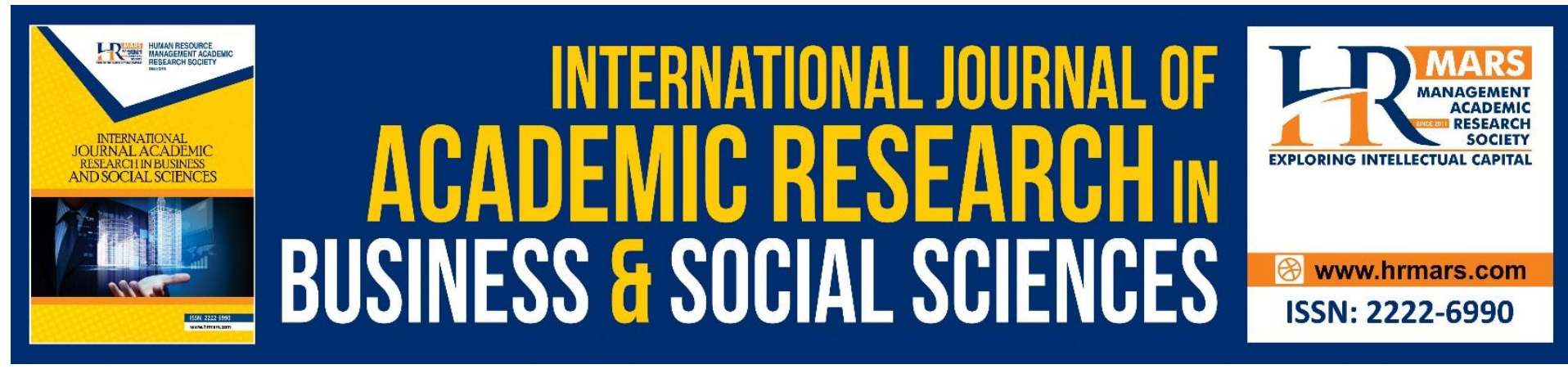

\title{
Intuitive Eating Behavior and Obesity among Adolescents in Malaysia
}

\author{
Rosmaliza Muhammad ${ }^{\text {, Norazmir Md Nor }}{ }^{\mathrm{a}}$, Emmy Hainida \\ Khairul Ikrama ${ }^{\mathrm{a}}$, Nurul Fadly Habidin ${ }^{\mathrm{b}}$, Norhayati Mohd Yusofa, \\ Norhidayah Abdullaha ${ }^{\mathrm{a}}$, Mohd Shazali Md Sharifa \\ aUniversiti Teknologi MARA, bUniversiti Pendidikan Sultan Idris, Malaysia
}

\begin{abstract}
Malaysia has witnessed a sharp increase in the prevalence of overweight and obesity in the past decade and named as the highest rate of overweight and obesity among all Southeast Asian countries by WHO in 2018. Despite the importance of the dietary knowledge intervention related to obesity and overweight, there is a lack of study on intuitive eating behaviour among Malaysian adolescents. Most of the existing overweight and obesity intervention was targeted to adolescents without considering the different psychological, cultures, religions, and ethnicities, making the current approaches less suitable for Malaysian adolescents. Therefore, it is important to understand how the Malaysian obese population benefits from the comprehensive, intuitive eating behaviour intervention. The improvement intervention based on intuitive eating behaviour that caters specifically towards Malaysian obese and overweight adolescents could contribute to develop effective healthcare intervention on obesity and overweight to ensure sustainable development of the community through prevention and control of non-communicable diseases enhancing population health safety through food consciousness.
\end{abstract}

Keywords: Intuitive Eating, Behaviour, Adolescents, Obesity, Malaysia.

\section{Introduction}

Nowadays, obesity is known as public health challenges, and more than 1.9 billion adults are encountered with overweight and obesity globally (WHO, 2017). WHO classified an individual as overweight when the body mass index (BMI) is $25.0-29.9 \mathrm{~kg} / \mathrm{m} 2$ and obese when the $\mathrm{BMI}$ is $\geq 30.0 \mathrm{~kg} / \mathrm{m} 2$. There are few terms of obesity used by scholars, such as abdominal obesity, abdominal adiposity, body fat percentage, and predictors for obesity (Ahmad et al., 2016). Body mass index (BMI) is the most commonly used parameter to measure abdominal obesity for determining whether someone may be defined as obese, overweight, or normal weight. BMI is the person's weight in kilograms divided by the square of the height in meters. WHO in 2015 reported that in 2014, more than 1.9 billion adults, 18 years and older, were overweight. Based on the figure, over 600 million were obese, whereby $39 \%$ of adults aged 18 years and over were overweight in 2014, and 13\% were obese. In addition, 42 million children under the age of 5 were overweight or obese in 2013 (WHO, 2015). 
In Malaysia, the prevalence of obesity has reached an upward trend. For instance, the Second National Health and Morbidity Survey in 1996 revealed the national prevalence of overweight and obesity as $16.6 \%$ and $4.4 \%$, respectively. Besides that, the mean body mass index (BMI) of Malaysian adults was $22.48 \mathrm{~kg} / \mathrm{m}$. In 2006, the national prevalence of overweight among Malaysian adult increased to $29.1 \%$, and obesity was $14.0 \%$. This figure has shown that in less than 20 years, the proportion of overweight adults has doubled whilst the obese proportion has tripled in Malaysia. Then, in 2015 the prevalence of obesity among female has doubled (29.6\%), and this prevalence was also found to be higher than men (25.0\%) (Institute for Public Health, 2015). In addition, the mean Body Mass Index (BMI) among housewives was also higher than other job categories (Mean BMI: $26.6 \mathrm{~kg} / \mathrm{m} 2$ ).

According to Chan, Lim, Hock Lim, Teh, Kee, Cheong, Khoo, Baharudin, Ling, Omar and Ahmad (2018), overweight and obesity occurred in Malaysia due to lifestyle changes as decreased physical activity (PA), increased sedentary behaviour and unhealthy eating habits. They also revealed that women are higher than men in obesity. The overweight and obesity problem may cause rising medical spending because some of those who have the problem may get treatment for diabetes and hypertension in hospitals and clinics. It shows that overweight and obese may lead to the disease (Mohamed et al., 2015). The risk of developing diabetes, gallstones, hypertension, heart disease, hyperlipidemia, stroke, and some forms of cancer is higher among obese people. Moreover, the risk of death is higher among moderately and severely overweight men and women, regardless of age. Among the near-elderly (ages 50-69), medical care spending among the severely obese (body mass index, or BMI, 35.0 or higher) is 60 per cent higher than for those of normal weight.

As previously mentioned, many factors are associated with obesity (Chan et al., 2018). Unhealthy eating patterns and lifestyle are the major cause of the problem. Hatta et al (2017) urged that obese and overweight people need to be motivated and understand healthy eating patterns to reduce the pain. Besides that, many scholars have conducted many studies on the obese population related to dietary knowledge, awareness, pattern and practice intervention program to explore in-depth related issues on obesity.

Despite the importance of the dietary knowledge intervention, there is a lack of study on intuitive eating behaviour among Malaysian adolescents. Furthermore, most of the existing overweight and obesity intervention was targeted to an adolescent without considering the different psychological, cultures, religions, and ethnicities of the adolescent, making the current approaches less suitable for Malaysian adolescents. Therefore, it is important to understand how the Malaysian obese population benefits from the comprehensive, intuitive eating behaviour intervention.

Therefore, to explore in-depth the related issue, the intuitive eating model will be applied. Healthy eating behaviour is most frequently operationalized in intuitive eating, which refers to eating behaviours characterized by a reliance on internal hunger and satiety cues. Individuals who eat intuitively are aware of and trust their body's physiological cues, give themselves unconditional permission to eat, are not preoccupied with food and dieting, and choose foods to support or enhance their body's functioning. Studies have shown that intuitive eating is associated with lower body mass and weight stability (Tylka, Calogero, \& Dan'ielsd'ottir, 2019) and lower gestational weight gain in community samples (Paterson et al., 2019).

Thus, examining the intuitive eating model in the Malaysian context would be useful, particularly as previous studies have not considered how intuitive eating may or may not differ across ethnic groups from the same nation. In addition, it raises questions on the factors 
that contribute to the intuitive eating behaviour among the Malaysian obese population, how the levels of intuitive eating behaviour among the Malaysian obese population relate to Malaysia healthcare improvement, and how a comprehensive, intuitive eating behaviour benefits the Malaysian obese population? Hence, this scope of study warrants to be explored.

\section{Literature Review}

In Malaysia Health Morbidity Survey 2011, the prevalence of obesity among female has doubled (29.6\%), and this prevalence was found to be higher than men (25.0\%) (Institute for Public Health, 2011). The National Health and Morbidity Survey (NHMS) study among Southeast Asian countries in 2011 also showed that Malaysia topped the list with the highest population of obese adults, at 44.2 per cent. In 2015, it shot up to 47.3 per cent (NHMS, 2015). This unpromising situation should be seriously monitored as overweight and obesity often is present together with systemic, low-grade and chronic inflammation usually associated with numerous life-threatening diseases (RodríguezHernández et al., 2013; Segula, 2014). Also, the Institute of Health's Second Burden of Disease Study for Malaysia, in 2012, singled out high blood pressure, smoking, diabetes, high cholesterol and overweight and obesity as the biggest contributors to disability and death. Based on the latest data, 1.65 million schoolchildren are expected to be overweight or obese by 2025 if nothing is done.

Most of the Malaysians are indeed an unhealthy population (Sani, 2019). However, he further revealed that the economic costs are equally shocking. On obesity, for instance, the country's total (direct and indirect) costs are the highest in ASEAN, accounting for between 10 per cent and 19 per cent of national healthcare spending (Sani, 2019). Therefore, trying to keep fit and maintaining a healthy lifestyle has always been a popular topic among Malaysians, particularly because they love food, love to eat, but they loathe exercise. For some, being healthy comes naturally by having a balanced diet and regular exercise. But for others, they eat more than they need, and due to this, Malaysia is Asia's fattest country, with approximately half of the population overweight or obese.

Intuitive eating involves consuming food following internal hunger and satiety cues (Tylka \& Diest, 2013). It is characterized by a strong physical connection to the body and a common preoccupation with food (Tribole \& Resch, 2012). Intuitive eating is predominantly measured by the Intuitive Eating Scale-2 (IES-2) (Tylka \& Diest, 2013). The IES-2 has four different aspects of intuitive eating. 'Unconditional Permission to Eat' (UPE) reflects the behaviour of eating whichever foods are desired at the moment. Foods are not categorized into allowed and forbidden foods. UPE can be considered an anti-diet attitude (Tribole \& Resch, 2012). 'Eating for Physical Rather Than Emotional Reasons' (EPR) assesses the ability to eat when physically hungry rather than using food to cope with negative emotions. EPR reflects an eating style that is not influenced by affective states. According to them, 'Reliance on Hunger and Satiety Cues' (RHSC) is the ability to rely on hunger and satiety cues to regulate food intake.

The perception of physiological states is the crucial feature of RHSC. 'Body-Food Choice Congruence' (B-FCC) reflects the choice of tasty and healthy nutrition in line with bodily needs. This aspect expands intuitive eating to include the concept of gentle nutrition that honours the health and body functioning (Tylka \& Van Diest, 2013). Besides that, the scholar found that self-regulation and intuitive eating are associated with a lower BMI (Camilleri et al., 2016; Keller \& Siegrist, 2014; Tylka \& Kroon Van Diest, 2013). Scholars revealed that that the autonomous regulation of eating behaviours (eating according to intrinsic motives) predicts intuitive eating (Carbonneau et al., 2015). 
Furthermore, one important component of self-regulation is emotion regulation that could hinder emotional eating. To eat in line with bodily needs, there is a constant demand for attention regulation and monitoring. Thus, a high level of self-regulation could support an intuitive eating behaviour. An intuitive eating behaviour could, in turn, result in a lower BMI (Tylka et al., 2019). Therefore, research on obesity and intuitive eating behaviour is important to be investigated.

\section{Conclusion}

Finding a basic model from this progress research for the intuitive eating behaviour for Malaysian obese population, especially the adolescents, is significant to encourage more studies to be conducted in the future because food intake is not the only way to control and prevent overweight and obesity to ensure good health and social well-being of the nation. A few attempts are still in progress to address health obliteration and correlate with the obesity and overweight problem in the healthcare industry.

\section{Acknowledgement}

This research was supported financially by Universiti Teknologi MARA under Special Research Grant: 600-RMC/GPK 5/3 (192/2020).

\section{Corresponding Author}

Rosmaliza Muhammad, Universiti Teknologi MARA, Malaysia, Faculty of Hotel and Tourism Management, Universiti Teknologi MARA, 42300 Puncak Alam, Selangor.

Email: rosmaliza35@uitm.edu.my

\section{References}

Ahmad, N., Adam, S. I. M., Nawi, A. M., Hassan, M. R., \& Ghazi, H. F. (2016). Abdominal obesity indicators: Waist circumference or waist-to-hip ratio in Malaysian adults population. International Journal of Preventive Medicine, (June). https://doi.org/10.4103/20087802.183654

Camilleri, G. M., M'ejean, C., Bellisle, F., Andreeva, V. A., Kesse-Guyot, E., Hercberg, S., \& P'eneau, S. (2016). Intuitive eating is inversely associated with body weight status in the general population-based NutriNet-Sant'e study. Obesity, 24, 1154-1161. http://dx.doi.org/10.1002/oby.21440

Carbonneau, E., Carbonneau, N., Lamarche, B., Provencher, V., Bégin, C., Bradette,M., \& Lemieux, S. (2016). Validation of a French-Canadian adaptation of thelntuitive Eating Scale-2 for the adult population. Appetite, 105, 37-45.

http://dx.doi.org/10.1016/j.appet.2016.05.001

Chan, Y. Y., Lim, K. K., Lim, K. H., Teh, C. H., Kee, C. C., Cheong, S. M., Khoo, Y. Y., Baharudin, A., Ling, M. Y., Omar, M. A., \& Ahmad, N. A. (2018), Physical activity and overweight/obesity among Malaysian adults: findings from the 2015 National Health and morbidity survey (NHMS). BioMed Central Public Health. 17: 733.

Paterson, H., Treharne, G. J., Horwath, C., Haszard, J. J., Herbisond, P., Smith , E. J. C. H. (2019). Intuitive eating and gestational weight gain, Eating Behaviors, 34, (2-5)

Mohamed, H. J. J., Yap, R. W. K., Loy, S. L., Norris, S. A., Biesma, R., \& Hansen, J. A. (2015). Prevalence and Determinants of Overweight, Obesity, and Type 2 Diabetes Mellitus in Adults in Malaysia. Asia Pacific Journal of Public Health. 27(2), 123-135. 
Hatta, N. K. B. M., Rahman, N. A. A., Rahman, N. I. A., \& Haque, M. (2017). Knowledge, Attitude and Practices among Mothers Regarding Childhood Obesity at Kuantan, Malaysia. International Medical. Medical Journal, Childhood obesity. 24 (2), 200- 204.

NHMS. (2006). The Third NHMS 2006, Nutritional Status, Institute for Public Health, National Institute of Health, Ministry of Health. http://iku.moh.gov.my/images/IKU/Document/REPORT/2006/NutritionalStatus.pdf

Sani, M. S. M. (2019). NST Leader: Fat hope? New Strait Times. Retrieved from https://www.nst.com.my/opinion/leaders/2019/07/501869/nst-leader-fat-hope

Segula, D. (2014). Complications of obesity in adults: A short review of literature. Malawi Medical Journal, 26(1).

Tribole, E., \& Resch, E. (2012). Intuitive Eating: A revolutionary program that works. New York: St. Martin's Press

Tylka, T. L., Calogero, R. M., \& Dan'ielsd'ottir, S. (2019). Intuitive eating is connected to selfreported weight stability in community women and men. Eating disorders, http://dx.doi.org/10.1080/10640266.2019.1580126.

Tylka, T. I., \& Van Diest, K. A. M. (2013). The intuitive Eating Scale 1: Item refinement and psychometric evaluation with college men and men. Journal of Counseling Psychology, 60, 137-153.

World Health Organization. (2015). Obesity and overweight. Media Centre. Fact Sheet, 311.2015. http://www.who.int/mediacentre/factsheets/fs311/en/ [Retrieved October 10, 2019]

World Health Organization. (2011). Non-communicable diseases country profiles 2011. Geneva: WHO, 2011

World Health Organization. (2017). Obesity and overweight fact sheet. Geneva. http://www.who.int/mediacentre/factsheets/fs311/ 